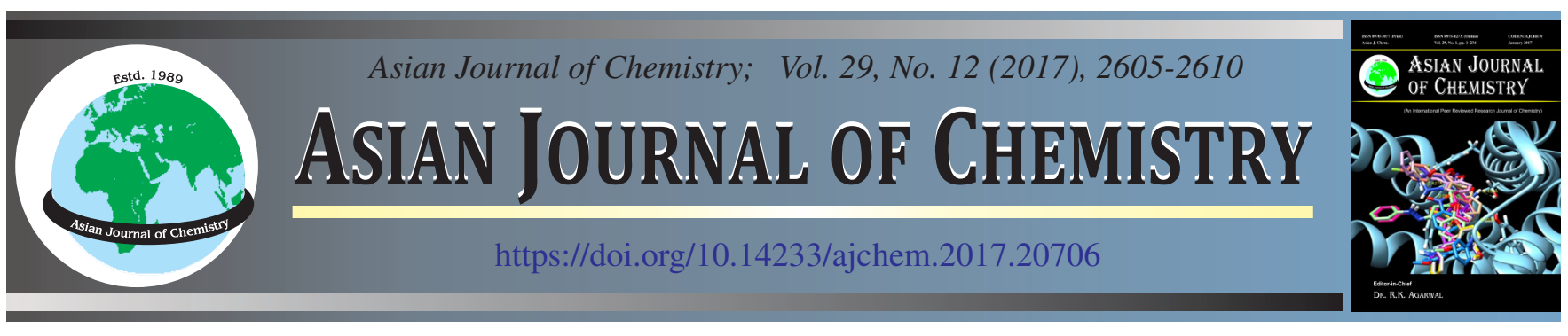

\title{
Effect of Temperature on Micellization Properties of Binary Mixtures of Sodium Tetradecylsulphate with Sodium Decylsulphate and Sodium Dodecylsulphate in Water
}

\section{O.G. SINGH}

Department of Chemistry, Moirang College, Manipur-795 133, India

Corresponding author: E-mail: oinamgobinsingh@yahoo.com

\begin{abstract}
Critical micelle concentration (CMC) values of binary mixtures of sodium tetradecylsulphate (STS) with sodium decylsulphate (SDeS) and sodium dodecylsulphate (SDS) in water have been determined using conductance measurement method at four different temperatures ranging from 298 to $313 \mathrm{~K}$ at $5 \mathrm{~K}$ intervals. The variation in CMC and counterion binding constant as a function of temperature have been investigated. Mixed micelle composition, activity coefficient of the components and mutual interaction between the components in the mixed micelle in terms of interaction parameter have been estimated using Rubingh's model. Variation of these mixed micellization parameters with temperature has been studied. The surfactant mixtures show attractive interaction between the components, which increases with increase in temperature. Thermodynamic parameters of mixed micellization have also been calculated and observed a linear correlation between the entropy change $\left(\Delta \mathrm{S}_{\text {mic }}^{\circ}\right)$ and enthalpy change $\left(\Delta \mathrm{H}^{\circ}{ }_{\text {mic }}\right)$.
\end{abstract}

Keywords: Sodium tetradecylsulphate, Sodium decylsulphate, Sodium dodecylsulphate, Mixed micelle, Counterion binding constant.

\section{INTRODUCTION}

Surface-active agents usually known as surfactants are found used in various fields. The wide range applicability of surfactants is attributed to their amphiphilic property. It is well known that mixtures of surfactants perform better than single surfactant systems. Therefore, many formulations developed for application in various fields consist of surfactant mixtures. Considering the importance of mixed surfactants systems, many researchers have done investigations on micellization properties of surfactant mixtures [1-18]. Recently, various possible combinations of surfactants are being studied [19-22]. However, systematic studies on the effect of temperature on micellization properties of mixed surfactants have been neglected, though there are many reported works [23-35] with regard to temperature effect on the micellization properties of single surfactant systems. Further, amongst the different types of surfactants studied, sodium alkylsulphate surfactants have been most extensively investigated. In view of these considerations, three homologues of sodium alkylsulphate viz. sodium decylsulphate (SDeS), sodium dodecylsulphate (SDS) and sodium tetradecylsulphate (STS) were chosen and studied the thermodynamic and micellization properties of the binary mixtures of STS with SDeS and SDS in water medium. Conductance measurements were made at four different temperatures ranging from 298 to $313 \mathrm{~K}$ at $5 \mathrm{~K}$ intervals to determine the

critical micelle concentration $(\mathrm{CMC})$ values at each temperature both for pure and binary mixed systems. Rubingh's model $[36,37]$ has been used to estimate mixed micelle composition, activity coefficient of the components and mutual interaction between the components in the mixed micelle. In this paper, effect of temperature on the mixed micellization properties and thermodynamic parameters of mixed micellization of the binary mixed surfactants systems studied are presented.

\begin{tabular}{l} 
EXPERIMENTAL \\
\hline The anionic surfactants, SDeS, SDS and STS were pur- \\
chased from Sigma-Aldrich Co. Ltd. and were used as received. \\
All solutions were prepared in double distilled water (specific \\
conductance, $\kappa$ was less than $2 \mu \mathrm{Sm}^{-1}$ at $298 \mathrm{~K}$ ). A binary \\
mixed surfactants solution of a particular composition was \\
prepared by weighing required amounts of the two surfactants \\
and dissolving them together. Small amounts of concentrated \\
surfactant solution were progressively added to a known \\
quantity of double distilled water using an Eppendorf pipette. \\
Conductance measurements were made after each addition of \\
the concentrated surfactant solution using Digital Conductivity \\
TDS Meter (Model 308, Systronics) with a dip type conduc- \\
tivity cell (cell constant $=1 \mathrm{~cm}^{-1}$ ) under controlled temperature \\
conditions using a water bath thermostat. The measurement of \\
weights were performed by using a SHIMADZU Balance \\
(Model ATX224).
\end{tabular}




\section{RESULTS AND DISCUSSION}

Critical micelle concentration (CMC): Representative plots of experimental values of specific conductance $(\kappa)$ versus total surfactant concentration $(\mathrm{C})$ at different temperatures for equimolar mixtures of; (a) STS + SDeS and (b) STS + SDS mixed systems are shown in Fig. 1. Similar plots (not shown) were obtained for other compositions also. From these plots, $\mathrm{CMC}$ values have been determined from the point of intersection of the two straight lines in the pre-micellar and postmicellar regions. The CMC values determined in this manner both for STS + SDeS and STS + SDS mixed systems are listed in Table-1. At a particular temperature, for the pure aqueous surfactant solutions, CMC values are in the order: SDeS > SDS $>$ STS. The observed CMC values for the pure aqueous surfactant solutions in the temperature range studied are comparable with previously reported [31]. The CMC values for both pure and binary mixed systems increase with increase in temperature in the investigated temperature range except for SDeS with a minimum at $303 \mathrm{~K}$. Such a minimum has been reported earlier for sodium alkylsulphate systems [30]. Generally, for both ionic and non-ionic surfactants, there exist a minimum in the $\mathrm{CMC}$-temperature curve and the temperature of minimum CMC increases with decrease in hydrophobicity of surfactants [32]. This may be the reason for SDS and STS not showing a minimum $\mathrm{CMC}$ in the temperature range studied.

The CMC of a binary mixed surfactants $\left(\mathrm{C}_{12}\right)$ is related to the bulk composition $(\alpha)$ and CMC's of components $\left(\mathrm{C}_{1}\right)$ and $\left(\mathrm{C}_{2}\right)$ by the relation $[36,37]$ :

$$
\begin{gathered}
\frac{1}{C_{12}}=\frac{\alpha_{1}}{f_{1} C_{1}}+\frac{\alpha_{2}}{f_{2} C_{2}} \\
f_{i}=\frac{\alpha_{i} C_{12}}{x_{i} C_{i}}
\end{gathered}
$$

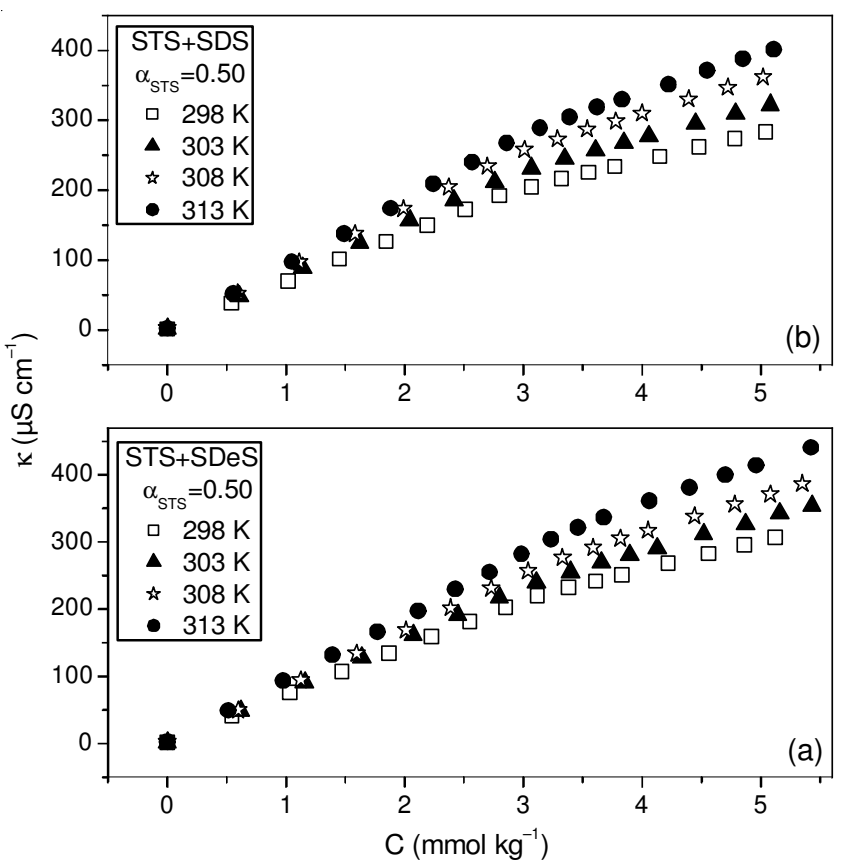

Fig. 1. Representative plots of specific conductance $(\kappa)$ against total surfactant concentration $(\mathrm{C})$ at different temperatures for equimolar mixtures of (a) STS + SDeS and (b) STS + SDS mixed systems

In eqn. $2, \mathrm{x}_{\mathrm{i}}$ and $\mathrm{f}_{\mathrm{i}}$ refer to mole fraction and activity coefficient of the $i^{\text {th }}$ component $(i=1$ for STS and $i=2$ for SDeS or $\mathrm{SDS})$ in the mixed micelle, respectively. For an ideal mixed micelle $\left(f_{1}=f_{2}=1\right)$, eqn. 1 reduces to the Clint's equation [38]:

$$
\frac{1}{\mathrm{C}_{12}}=\frac{\alpha_{1}}{\mathrm{C}_{1}}+\frac{\alpha_{2}}{\mathrm{C}_{2}}
$$

From Table-1, it is observed that the experimental CMC values of the binary mixtures are less than the ideal CMC values, which were obtained using eqn. 3 , thereby indicating synergism in the studied temperature range.

\begin{tabular}{|c|c|c|c|c|c|c|c|}
\hline \multirow{2}{*}{$\alpha_{\mathrm{STS}}$} & \multirow{2}{*}{$\mathrm{T}(\mathrm{K})$} & \multicolumn{3}{|c|}{ STS + SDeS } & \multicolumn{3}{|c|}{ STS + SDS } \\
\hline & & $\mathrm{CMC}\left(\mathrm{mmol} \mathrm{kg}{ }^{-1}\right)$ & $\beta_{\mathrm{C}}$ & $\mathrm{x}_{\text {STS }}^{*}$ & $\mathrm{CMC}\left(\mathrm{mmol} \mathrm{kg}{ }^{-1}\right)$ & $\beta_{\mathrm{C}}$ & $\mathrm{x}_{\mathrm{STS}}^{*}$ \\
\hline \multirow{4}{*}{0} & 298 & 33.0 & 0.54 & - & 8.0 & 0.60 & - \\
\hline & 303 & 32.8 & 0.53 & - & 8.1 & 0.59 & - \\
\hline & 308 & 33.0 & 0.53 & - & 8.3 & 0.58 & - \\
\hline & 313 & 33.4 & 0.52 & - & 8.6 & 0.57 & - \\
\hline \multirow{4}{*}{0.25} & 298 & $5.00\left(6.86^{\mathrm{a}}\right)$ & 0.22 & 0.844 & $4.12\left(4.61^{a}\right)$ & 0.38 & 0.568 \\
\hline & 303 & $5.07(7.05)$ & 0.22 & 0.839 & $4.18(4.72)$ & 0.37 & 0.562 \\
\hline & 308 & $5.15(7.28)$ & 0.21 & 0.835 & $4.30(4.88)$ & 0.36 & 0.559 \\
\hline & 313 & $5.28(7.62)$ & 0.21 & 0.829 & $4.47(5.10)$ & 0.35 & 0.555 \\
\hline \multirow{4}{*}{0.50} & 298 & $3.06(3.82)$ & 0.39 & 0.942 & $2.84(3.24)$ & 0.42 & 0.798 \\
\hline & 303 & $3.10(3.95)$ & 0.37 & 0.940 & $2.90(3.33)$ & 0.41 & 0.794 \\
\hline & 308 & $3.18(4.09)$ & 0.36 & 0.938 & $2.97(3.45)$ & 0.40 & 0.792 \\
\hline & 313 & $3.32(4.30)$ & 0.35 & 0.936 & $3.10(3.63)$ & 0.39 & 0.789 \\
\hline \multirow{4}{*}{0.75} & 298 & $2.52(2.65)$ & 0.50 & 0.980 & $2.40(2.50)$ & 0.53 & 0.922 \\
\hline & 303 & $2.54(2.74)$ & 0.48 & 0.979 & $2.45(2.58)$ & 0.53 & 0.920 \\
\hline & 308 & $2.60(2.84)$ & 0.47 & 0.978 & $2.50(2.67)$ & 0.52 & 0.919 \\
\hline & 313 & $2.70(3.00)$ & 0.46 & 0.978 & $2.59(2.82)$ & 0.51 & 0.918 \\
\hline \multirow{4}{*}{1.00} & 298 & 2.03 & 0.65 & - & 2.03 & 0.65 & - \\
\hline & 303 & 2.10 & 0.64 & - & 2.10 & 0.64 & - \\
\hline & 308 & 2.18 & 0.63 & - & 2.18 & 0.63 & - \\
\hline & 313 & 2.30 & 0.62 & - & 2.30 & 0.62 & - \\
\hline
\end{tabular}

\section{TABLE-1}

VALUES OF CMC, $\beta_{\mathrm{C}}$ AND $\mathrm{x}_{\text {STS }}^{*}$ FOR STS + SDeS AND STS + SDS MIXED SYSTEMS IN WATER AT DIFFERENT TEMPERATURES

${ }^{\mathrm{a}} \mathrm{CMC}$ value obtained from Clint's equation 
Mixed micelle composition: Rubingh's model employed the regular solution approximation to describe the non-ideality in the mixed micelle $[36,37]$. According to this approximation, non-ideality in the mixed micelle is described in terms of the interaction parameter $\left(\beta_{\mathrm{m}}\right)$ and is related to the activity coefficient by the relation:

$$
\beta_{\mathrm{m}}=\frac{\ln \mathrm{f}_{1}}{\left(1-\mathrm{x}_{1}\right)^{2}}=\frac{\ln \mathrm{f}_{2}}{\mathrm{x}_{1}^{2}}
$$

On substituting for the activity coefficients in eqn. 4, we get the expression:

$$
x_{1}^{2} \ln \frac{\alpha_{1} C_{12}}{x_{1} C_{1}}=\left(1-x_{1}\right)^{2} \ln \frac{\left(1-\alpha_{1}\right) C_{12}}{\left(1-x_{1}\right) C_{2}}
$$

At a particular bulk composition $\alpha_{1}$, values of mole fraction of component 1 in the mixed micelle $\mathrm{x}_{1}$ at different temperatures were computed from eqn. 5 by using an iterative method. The $\mathrm{x}_{1}$ values obtained in this manner are shown in Fig. 2 as a variation of $x_{S T S}^{R b}$ with temperature. Under the condition of ideality $\left(f_{1}=f_{2}=1\right), x_{1}$ takes the form:

$$
\mathrm{x}_{1}=\frac{\alpha_{1} \mathrm{C}_{2}}{\alpha_{1} \mathrm{C}_{2}+\alpha_{2} \mathrm{C}_{1}}
$$

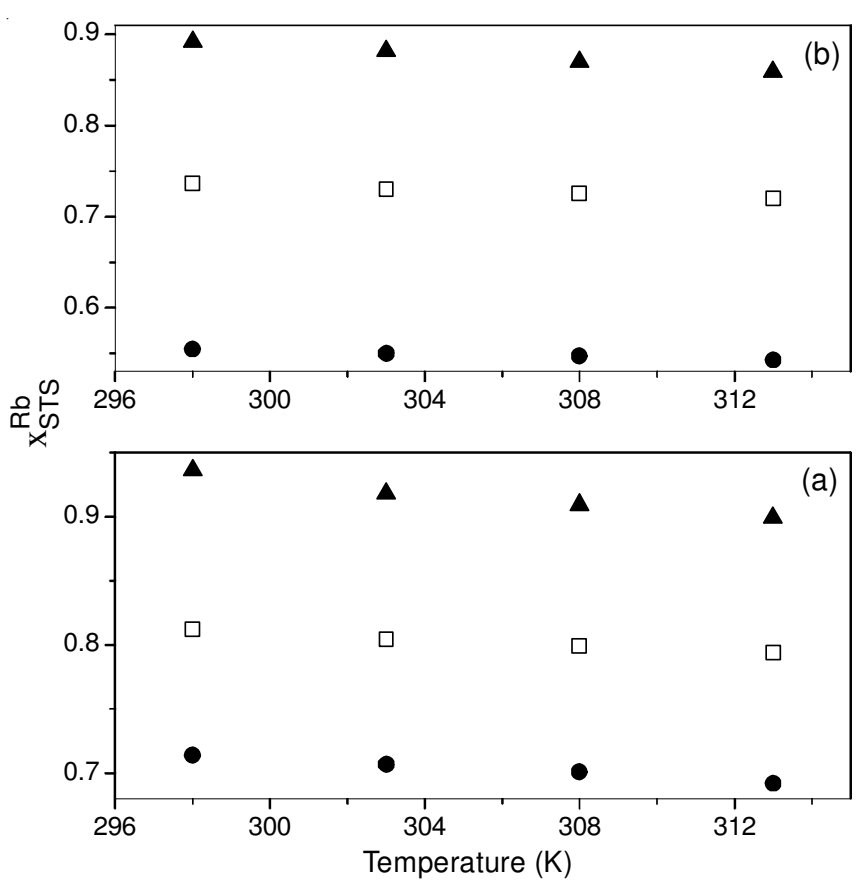

Fig. 2. Values of mole fraction of STS in the mixed micelle ( $\left.x_{S T S}^{R b}\right)$ as a function of temperature for (a) STS + SDeS and (b) STS + SDS mixed systems. (•) $\alpha_{\mathrm{STS}}=0.25 ;(\boldsymbol{\square}) \alpha_{\mathrm{STS}}=0.50 ;(\mathbf{\Delta}) \alpha_{\mathrm{STS}}=0.75$

The ideal values of $x_{1}$ calculated employing eqn. 6 are

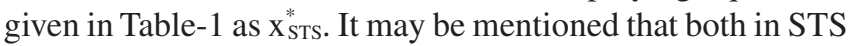
+ SDeS and STS + SDS mixed systems $x_{S T S}^{R b}$ is slightly less than $\mathrm{x}_{\mathrm{STS}}^{*}$. Further, it observed that in both the mixed systems studied, the mixed micelle is enriched with the surfactant component with lower CMC value (higher homologue). Similar observation of enrichment of the mixed micelle with the surfactant component with lower CMC was made in SDS + SDeS system studied earlier [39]. It is also evident from Fig. 2 that the degree of enrichment of the mixed micelle by
STS is more in STS + SDeS system than that in STS + SDS system. This is because the CMC of SDeS is about 16 times the CMC of STS whereas the CMC of SDS is only about 4 times the CMC of STS. In general, the enrichment of the mixed micelle by STS in the present study show appreciable decrease with increase in temperature.

The activity coefficient $f_{i}(i=1$ for STS and $i=2$ for SDeS or SDS) values at different temperatures were calculated using eqn. 2 and by employing the $\mathrm{x}_{1}$ values which were computed using eqn. 5 . The calculated values of $\mathrm{f}_{\mathrm{STS}}, \mathrm{f}_{\mathrm{SDeS}}$ and $\mathrm{f}_{\mathrm{SDS}}$ are shown as function of temperature in Fig. 3. Activity coefficient represents the effect and contribution of an individual component in the mixed micelle. In both the mixed systems studied, the $\mathrm{f}_{\text {STS }}$ values are high, indicating that the STS component in the mixed micelle is close to its standard state. In general, the activity coefficient of the components decreases with increase in temperature.

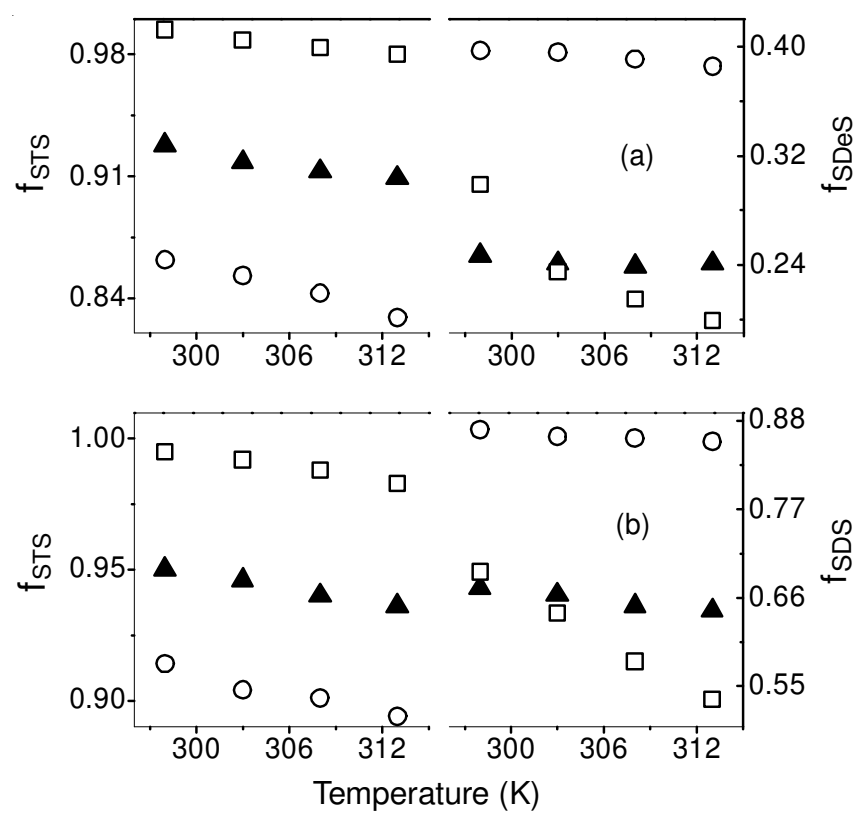

Fig. 3. Values of activity coefficient (f) of the components as a function of temperature for (a) STS + SDeS and (b) STS + SDS mixed systems. (O) $\alpha_{\mathrm{STS}}=0.25 ;(\mathbf{\Delta}) \alpha_{\mathrm{STS}}=0.50 ;(\boldsymbol{\square}) \alpha_{\mathrm{STS}}=0.75$

The values of the interaction parameter $\beta_{\mathrm{m}}$ determined using eqn. 4 at different temperatures are shown as function of temperature in Fig. 4. In both STS + SDeS and STS + SDS mixed systems, $\beta_{\mathrm{m}}$ values are negative indicating attractive interaction between the anionic surfactant components. It is observed that more negative values of $\beta_{\mathrm{m}}$ (stronger attractive interaction) are found in STS + SDeS system than that in STS + SDS system. Stronger attractive interaction is expected in binary mixed systems of homologous surfactants with greater difference in the hydrocarbon chain between the components. It is evident from Fig. 4 that in both the mixed systems, strongest attractive interaction between the components exists in the equimolar mixtures. Further, the dependence of $\beta_{\mathrm{m}}$ on temperature is found to be strongest in both the mixed systems when the mixtures have bulk composition, $\alpha_{\mathrm{STS}}=0.75$. In general, the attractive interaction between the components in both the mixed systems is found to increase with increase in temperature. 


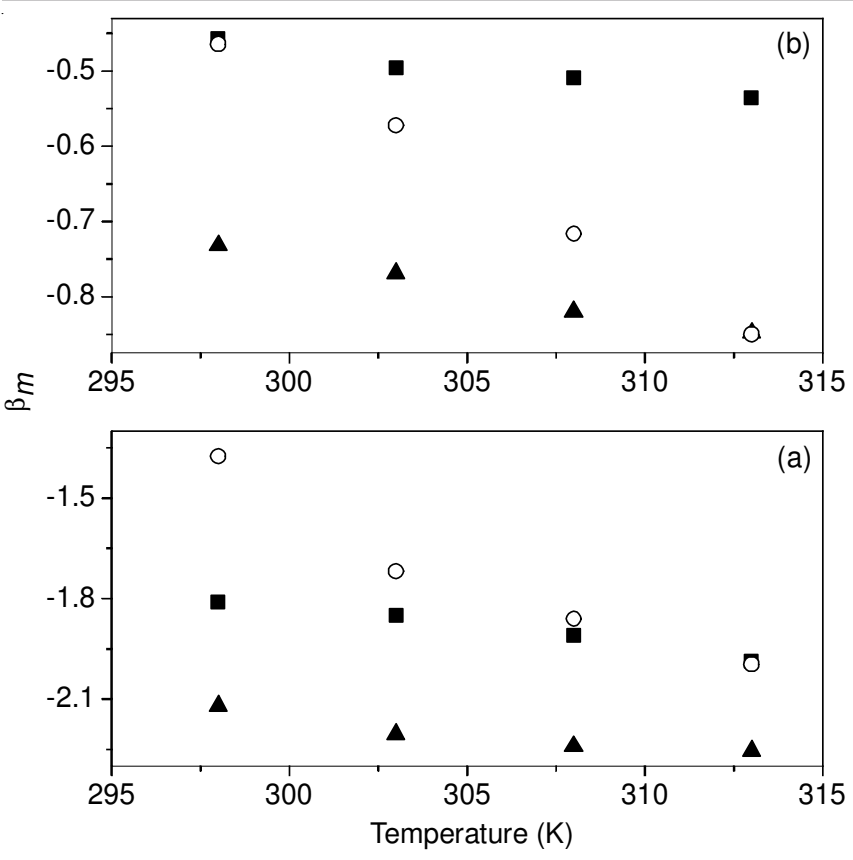

Fig. 4. Values of interaction parameter in the mixed micelle $\left(\beta_{\mathrm{m}}\right)$ as a function of temperature for (a) STS + SDeS and (b) STS + SDS mixed systems. ( $\boldsymbol{\square}) \alpha_{\mathrm{STS}}=0.25 ;(\boldsymbol{\Delta}) \alpha_{\mathrm{STS}}=0.50 ;$ (O) $\alpha_{\mathrm{STS}}=0.75$

Counter ion binding constant: The slope ratio method has been used to evaluate the counterion binding constant $\left(\beta_{\mathrm{C}}\right)$ values of both pure and mixed surfactants systems. In this method, $\beta_{\mathrm{C}}$ is calculated using the relation:

$$
\beta_{\mathrm{C}}=1-\frac{\mathrm{S}_{2}}{\mathrm{~S}_{1}}
$$

where, $S_{1}$ and $S_{2}$ are the slopes of the specific conductance ( $\left.\kappa\right)$ versus surfactant concentration $(\mathrm{C})$ plots in the pre and post micellar regions, respectively. The calculated $\beta_{\mathrm{C}}$ values are given in Table-1. At a particular temperature, for the pure aqueous surfactant solutions, $\beta_{C}$ values are in the order: STS > SDS > SDeS. It may be mentioned that the $\beta_{\mathrm{C}}$ values for pure SDeS and SDS in the temperature range studied are not very far from the values reported earlier using conductivity method at similar temperatures [23]. The $\beta_{\mathrm{C}}$ value decreases slightly with increase in temperature which may be due to decrease in the aggregation number of the micelle [40]. However, $\beta_{C}$ has a weak dependence on temperature. It may also be pointed out that $\beta_{\mathrm{C}}$ values of the mixed micelles are lower than those of pure micelles. The low $\beta_{\mathrm{C}}$ values for mixed micelles means that the effective surface charge density is less in the mixed micelles than that in the pure micelles. Similar observation of low $\beta_{C}$ values for mixed micelles has been reported for equimolar; CTAB + TTAB, CTAB + DTAB and TTAB + DTAB mixed systems [2].

Thermodynamic parameters of micellization: The standard Gibbs free energy of micellization per mole of surfactant, $\left(\Delta \mathrm{G}_{\text {mic }}^{\circ}\right)$ of the studied surfactant systems has been obtained using the relation $[32,41]$ :

$$
\Delta \mathrm{G}_{\mathrm{mic}}^{\mathrm{o}}=\left(1+\beta_{\mathrm{C}}\right) \mathrm{RT} \ln \mathrm{X}_{\mathrm{CMC}}
$$

where, $\mathrm{R}$ is the gas constant $\left(8.314 \mathrm{JK}^{-1} \mathrm{~mol}^{-1}\right)$, $\mathrm{T}$ is absolute temperature and $\mathrm{X}_{\mathrm{CMC}}$ is the $\mathrm{CMC}$ in mole fraction unit. The corresponding enthalpy change of micellization, $\Delta \mathrm{H}_{\text {mic }}^{\circ}$, is:

$$
\Delta \mathrm{H}_{\text {mic }}^{\mathrm{o}}=-\mathrm{RT}^{2}\left[\left(1+\beta_{\mathrm{C}}\right)\left(\frac{\partial \ln \mathrm{X}_{\mathrm{CMC}}}{\partial \mathrm{T}}\right)_{\mathrm{P}}+\ln \mathrm{X}_{\mathrm{CMC}}\left(\frac{\partial \beta_{\mathrm{C}}}{\partial \mathrm{T}}\right)_{\mathrm{P}}\right]
$$

Since the change in $\beta_{C}$ with temperature is small in the temperature range investigated, eqn. 9 becomes:

$$
\Delta \mathrm{H}_{\mathrm{mic}}^{\mathrm{o}}=-\mathrm{RT}^{2}\left[\left(1+\beta_{\mathrm{C}}\right)\left(\frac{\partial \ln \mathrm{X}_{\mathrm{CMC}}}{\partial \mathrm{T}}\right)_{\mathrm{P}}\right]
$$

$\Delta \mathrm{H}_{\text {mic }}^{\circ}$ values have been estimated using eqn. 10. For this purpose, $\ln \mathrm{X}_{\mathrm{CMC}}$ was plotted against $\mathrm{T}$ and the slopes determined at each temperature is taken as $\left(\frac{\partial \ln \mathrm{X}_{\mathrm{CMC}}}{\partial \mathrm{T}}\right)_{\mathrm{P}}$. Once $\Delta \mathrm{G}_{\text {mic }}^{\circ}$ and $\Delta \mathrm{H}_{\text {mic }}^{\circ}$ have been estimated, the entropic contribution has been obtained using the relation:

$$
\Delta \mathrm{G}_{\text {mic }}^{\mathrm{o}}=\Delta \mathrm{H}_{\text {mic }}^{\mathrm{o}}-\mathrm{T} \Delta \mathrm{S}_{\text {mic }}^{\mathrm{o}}
$$

The thermodynamic parameters of micellization, $\Delta \mathrm{G}_{\mathrm{mic}}^{\circ}$, $\Delta \mathrm{H}_{\text {mic }}^{\circ}$ and $\Delta \mathrm{S}_{\text {mic }}^{\circ}$ for the investigated surfactant systems are given in Tables 2 and 3. It is observed that both for pure and mixed surfactants systems, $\Delta \mathrm{G}_{\text {mic }}^{\circ}$ becomes more negative with increase in temperature. It is also evident that the enthalpy of micellization becomes more negative and the associated London-dispersion interaction plays a more predominant role as the temperature increases. The entropic contribution of micelle formation $\left(\mathrm{T} \Delta \mathrm{S}_{\mathrm{mic}}^{\circ}\right)$ has positive values and it decreases with rise in temperature. This shows that micellization process is entropy controlled at lower temperatures while at higher temperatures, it is enthalpy controlled.

The phenomenon of enthalpy-entropy compensation has been observed in a variety of processes, including the micelle formation of surfactants $[32,33,42,43]$. This phenomenon is reflected by a linear relationship between the enthalpy change and the entropy change and can be expressed by:

$$
\Delta \mathrm{H}_{\mathrm{mic}}^{\mathrm{o}}=\Delta \mathrm{H}_{\mathrm{m}}^{*}-\mathrm{T}_{\mathrm{C}} \Delta \mathrm{S}_{\mathrm{mic}}^{\mathrm{o}}
$$

In order to analyze this possibility, the plots of $\Delta \mathrm{H}_{\text {mic }}^{\circ}$ versus $\Delta \mathrm{S}_{\mathrm{mic}}^{\circ}$ i.e. the so-called compensation plot have been considered. According to the conceptual scheme of compensation phenomenon proposed by Lumry and Rajender [43], micelle formation process can be divided into (i) desolvation part and (ii) chemical part. The slope of the compensation plot $\left(\mathrm{T}_{\mathrm{C}}\right)$ known as the compensation temperature, provides a measure of the desolvation part of micellization. The intercept $\left(\Delta \mathrm{H}_{\mathrm{m}}^{*}\right)$ gives information of the solute-solute interaction and reflects the effectiveness of the chemical part of the micelle formation. The compensation plots for STS + SDeS and STS + SDS mixed systems are shown in Fig. 5. A linear correlation between the enthalpy and entropy of micellization has been observed for all the surfactant systems studied. The values of $\Delta \mathrm{H}_{\mathrm{m}}^{*}$ and $\mathrm{T}_{\mathrm{C}}$ both for pure and mixed surfactants obtained from the compensation plots are given in Tables 2 and 3. In both the mixed systems, $\Delta \mathrm{H}_{\mathrm{m}}^{*}$ becomes less negative on initial addition of STS but on further addition it becomes more negative. It has been reported that $\Delta \mathrm{H}_{\mathrm{m}}^{*}$ decreases (becomes more negative) with an increase in the alkyl chain length of surfactants in a homologous series and a more negative value of $\Delta \mathrm{H}_{\mathrm{m}}^{*}$ means greater stability of the structure of the micelle [32]. Therefore, it may 
TABLE-2

THERMODYNAMIC PARAMETERS OF MICELLIZATION FOR STS + SDES SYSTEM IN WATER AT DIFFERENT TEMPERATURES

\begin{tabular}{|c|c|c|c|c|c|c|}
\hline$\alpha_{\mathrm{STS}}$ & $\mathrm{T}(\mathrm{K})$ & $\Delta \mathrm{G}_{\text {mic }}^{\circ}\left(\mathrm{kJ} \mathrm{mol}^{-1}\right)$ & $\Delta \mathrm{H}_{\text {mic }}^{\circ}\left(\mathrm{kJ} \mathrm{mol}^{-1}\right)$ & $\mathrm{T} \Delta \mathrm{S}_{\text {mic }}^{\circ}\left(\mathrm{kJ} \mathrm{mol}^{-1}\right)$ & $\Delta \mathrm{H}_{\mathrm{m}}^{*}\left(\mathrm{~kJ} \mathrm{~mol}^{-1}\right)$ & $\mathrm{T}_{\mathrm{C}}(\mathrm{K})$ \\
\hline \multirow{4}{*}{0} & 298 & -28.35 & 2.13 & 30.48 & \multirow{4}{*}{-27.5} & \multirow{4}{*}{290} \\
\hline & 303 & -28.66 & 0.07 & 28.73 & & \\
\hline & 308 & -29.11 & -2.11 & 27.00 & & \\
\hline & 313 & -29.34 & -4.41 & 24.93 & & \\
\hline \multirow{4}{*}{0.25} & 298 & -28.16 & -1.74 & 26.42 & \multirow{4}{*}{-26.7} & \multirow{4}{*}{282} \\
\hline & 303 & -28.59 & -2.82 & 25.76 & & \\
\hline & 308 & -28.77 & -3.95 & 24.82 & & \\
\hline & 313 & -29.16 & -5.16 & 24.00 & & \\
\hline \multirow{4}{*}{0.50} & 298 & -33.77 & -0.91 & 32.86 & \multirow{4}{*}{-31.5} & \multirow{4}{*}{278} \\
\hline & 303 & -33.80 & -4.07 & 29.73 & & \\
\hline & 308 & -34.02 & -7.40 & 26.61 & & \\
\hline & 313 & -34.16 & -10.90 & 23.27 & & \\
\hline \multirow{4}{*}{0.75} & 298 & -37.17 & -0.14 & 37.02 & \multirow{4}{*}{-34.8} & \multirow{4}{*}{280} \\
\hline & 303 & -37.26 & -3.52 & 33.74 & & \\
\hline & 308 & -37.53 & -7.07 & 30.46 & & \\
\hline & 313 & -37.73 & -10.80 & 26.94 & & \\
\hline \multirow{4}{*}{1.00} & 298 & -41.77 & -6.44 & 35.33 & \multirow{4}{*}{-39.6} & \multirow{4}{*}{280} \\
\hline & 303 & -42.07 & -9.08 & 32.99 & & \\
\hline & 308 & -42.35 & -11.85 & 30.49 & & \\
\hline & 313 & -42.54 & -14.76 & 27.78 & & \\
\hline
\end{tabular}

TABLE-3

THERMODYNAMIC PARAMETERS OF MICELLIZATION FOR STS + SDS SYSTEM IN WATER AT DIFFERENT TEMPERATURES

\begin{tabular}{|c|c|c|c|c|c|c|}
\hline$\alpha_{\mathrm{STS}}$ & $\mathrm{T}(\mathrm{K})$ & $\Delta \mathrm{G}_{\text {mic }}^{\circ}\left(\mathrm{kJ} \mathrm{mol}^{-1}\right)$ & $\Delta \mathrm{H}_{\text {mic }}^{\circ}\left(\mathrm{kJ} \mathrm{mol}^{-1}\right)$ & $\mathrm{T} \Delta \mathrm{S}_{\text {mic }}^{\circ}\left(\mathrm{kJ} \mathrm{mol}^{-1}\right)$ & $\Delta \mathrm{H}_{\mathrm{m}}^{*}\left(\mathrm{~kJ} \mathrm{~mol}^{-1}\right)$ & $\mathrm{T}_{\mathrm{C}}(\mathrm{K})$ \\
\hline \multirow{4}{*}{0} & 298 & -35.06 & -1.61 & 33.46 & \multirow{4}{*}{-33.5} & \multirow{4}{*}{284} \\
\hline & 303 & -35.38 & -4.45 & 30.93 & & \\
\hline & 308 & -35.64 & -7.45 & 28.19 & & \\
\hline & 313 & -35.84 & -10.59 & 25.25 & & \\
\hline \multirow{4}{*}{0.25} & 298 & -32.51 & -1.84 & 30.67 & \multirow{4}{*}{-30.7} & \multirow{4}{*}{281} \\
\hline & 303 & -32.77 & -4.43 & 28.34 & & \\
\hline & 308 & -32.97 & -7.15 & 25.81 & & \\
\hline & 313 & -33.12 & -10.01 & 23.11 & & \\
\hline \multirow{4}{*}{0.50} & 298 & -34.76 & -2.56 & 32.20 & \multirow{4}{*}{-32.6} & \multirow{4}{*}{278} \\
\hline & 303 & -35.02 & -4.99 & 30.03 & & \\
\hline & 308 & -35.26 & -7.54 & 27.72 & & \\
\hline & 313 & -35.42 & -10.22 & 25.21 & & \\
\hline \multirow{4}{*}{0.75} & 298 & -38.10 & -3.12 & 34.97 & \multirow{4}{*}{-35.9} & \multirow{4}{*}{279} \\
\hline & 303 & -38.66 & -4.95 & 33.71 & & \\
\hline & 308 & -38.96 & -6.85 & 32.11 & & \\
\hline & 313 & -39.19 & -8.84 & 30.35 & & \\
\hline \multirow{4}{*}{1.00} & 298 & -41.77 & -6.44 & 35.33 & \multirow{4}{*}{-39.6} & \multirow{4}{*}{280} \\
\hline & 303 & -42.07 & -9.08 & 32.99 & & \\
\hline & 308 & -42.35 & -11.85 & 30.49 & & \\
\hline & 313 & -42.54 & -14.76 & 27.78 & & \\
\hline
\end{tabular}

be inferred that addition of higher homologue (STS) to either SDeS or SDS results in a more stable micelle by enhancing the effect of chemical part of micellization.

The desolvation part of micellization process has been reported to be independent of the alkyl chain length of surfactants in a homologous series [32]. In the present STS + SDeS and STS + SDS mixed systems, the $\mathrm{T}_{\mathrm{C}}$ values are found to be $282 \pm 4 \mathrm{~K}$ and $280 \pm 2 \mathrm{~K}$, respectively and are within the suggested range of 270-294 K for the water system [33].

\section{Conclusion}

Conductance measurement method has been used to determine the CMC and counterion binding constant values for STS + SDeS and STS + SDS mixed systems at four different temperatures ranging from 298 to $313 \mathrm{~K}$ at $5 \mathrm{~K}$ intervals. These data were used to derive some of the parameters of micellization. In the investigated temperature range, CMC increases whereas counterion binding constant decreases slightly with increase in temperature. In both the mixed systems the mixed micelles are enriched with the surfactant component having lower CMC (STS) and the attractive interaction between the components increases with increase in temperature. Micellization, either in pure or in mixed state, is found to be entropy driven at low temperatures while at high temperatures it is enthalpy driven. The enthalpy and entropy terms of micellization compensate each other, resulting in moderate decrease in the Gibbs energy. 


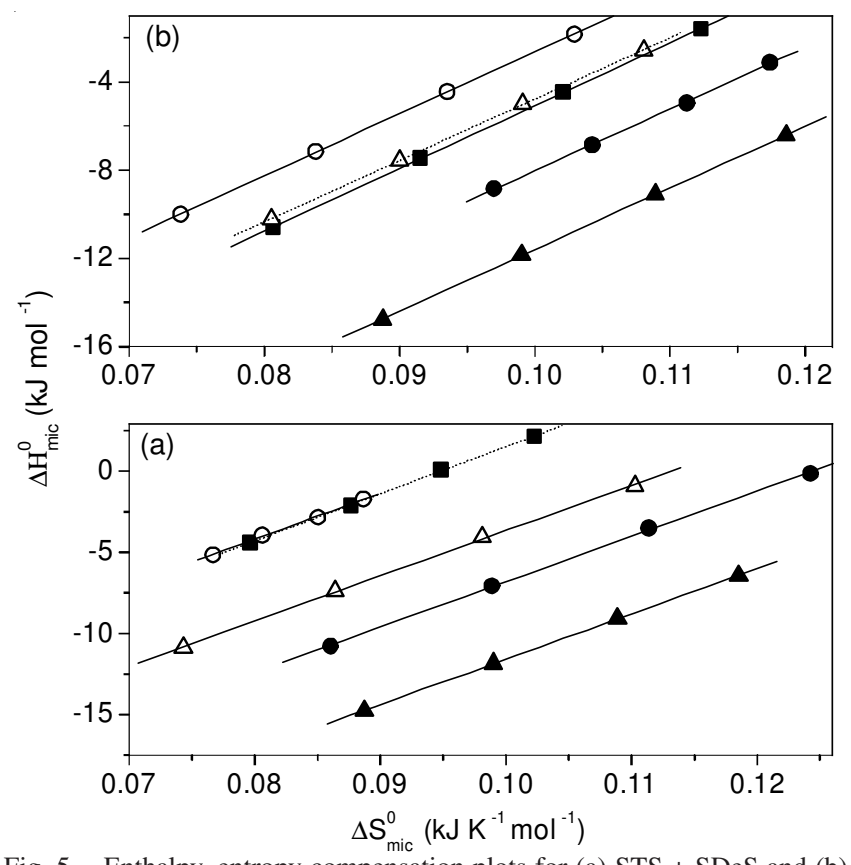

Fig. 5. Enthalpy-entropy compensation plots for (a) STS + SDeS and (b) STS + SDS mixed systems. ( $) \alpha_{\text {STS }}=0 ;(0) \alpha_{\text {STS }}=0.25 ;(\Delta) \alpha_{\text {STS }}$ $=0.50$;

$$
\text { (A) } \alpha_{\mathrm{STS}}=1
$$

\section{ACKNOWLEDGEMENTS}

Financial support received from the University Grants Commission-NERO, Guwahati, India, under the Minor Research Project No. F. 5-86/2014-15/MRP/NERO is thankfully acknowledged. The author is also thankful to Moirang College Biotech Hub, Manipur, India, for providing necessary laboratory facilities for the work.

\section{REFERENCES}

1. Y. Moroi, N. Nishikido and R. Matuura, J. Colloid Interface Sci., 50, 344 (1975);

https://doi.org/10.1016/0021-9797(75)90238-6.

2. S.P. Moulik, M.E. Haque, P.K. Jana and A.R. Das, J. Phys. Chem., 100, 701 (1996);

https://doi.org/10.1021/jp9506494.

3. A.D. Burman, T. Dey, B. Mukherjee and A.R. Das, Langmuir, 16, 10020 (2000);

https://doi.org/10.1021/la000610c.

4. M. Bergström, Langmuir, 17, 993 (2001); https://doi.org/10.1021/la000814t.

5. L. Chen, J.-X. Xiao, K. Ruan and J. Ma, Langmuir, 18, 7250 (2002); https://doi.org/10.1021/la025878d.

6. J.K. Angarska, K.D. Tachev and N.D. Denkov, Colloids Surf. A, 233, 193 (2004); https://doi.org/10.1016/j.colsurfa.2003.11.020.

7. T. Matsuda, M. Aratono, Y. Asoh, M. Villeneuve, H. Matsubara and T. Takiue, Colloid Polym. Sci., 282, 324 (2004); https://doi.org/10.1007/s00396-003-0931-0.

8. M.S. Bakshi, I. Kaur, R. Sood and K. Singh, Colloid Polym. Sci., 281, 771 (2003); https://doi.org/10.1007/s00396-002-0823-8.

9. M. Manabe, M. Funamoto, F. Kohgami, H. Kawamura and H. Katsuura, Colloid Polym. Sci., 281, 239 (2003); https://doi.org/10.1007/s00396-002-0764-2.

10. K. Motomura, M. Yamanaka and M. Aratono, Colloid Polym. Sci., 262, 948 (1984);

https://doi.org/10.1007/BF01490027.

11. A.J. Prosser and E.I. Franses, J. Colloid Interface Sci., 263, 606 (2003); https://doi.org/10.1016/S0021-9797(03)00346-1.
12. H. Maeda, J. Colloid Interface Sci., 258, 390 (2003); https://doi.org/10.1016/S0021-9797(02)00128-5.

13. V.M. Garamus, Langmuir, 19, 7214 (2003); https://doi.org/10.1021/1a034481m.

14. J.F. Rathman and J.F. Scamehorn, Langmuir, 2, 354 (1986); https://doi.org/10.1021/la00069a019.

15. P.C. Griffiths, A.Y.F. Cheung, G.J. Finney, C. Farley, A.R. Pitt, A.M. Howe, S.M. King, R.K. Heenan and B.L. Bales, Langmuir, 18, 1065 (2002); https://doi.org/10.1021/la011163j.

16. T. Chakraborty and S. Ghosh, Colloid Polym. Sci., 285, 1665 (2007); https://doi.org/10.1007/s00396-007-1738-1.

17. O.G. Singh and K. Ismail, J. Surfactants Deterg., 11, 89 (2008); https://doi.org/10.1007/s11743-007-1058-y.

18. M. Jan, A.A. Dar and G.M. Rather, Colloids Surf. A, 335, 114 (2009); https://doi.org/10.1016/j.colsurfa.2008.10.036.

19. A. Maneedaeng, K.J. Haller, B.P. Grady and A.E. Flood, J. Colloid Interface Sci., 356, 598 (2011); https://doi.org/10.1016/j.jcis.2011.01.008.

20. L.-S. Hao, Y.-T. Deng, L.-S. Zhou, H. Ye, Y.-Q. Nan and P. Hu, J. Phys. Chem. B, 116, 5213 (2012); https://doi.org/10.1021/jp300568k.

21. O.G. Singh and K. Ismail, Colloids Surf. A, 414, 209 (2012); https://doi.org/10.1016/j.colsurfa.2012.08.025.

22. N.A. Negm, M.R. Mishrif and D.E. Mohamed, Colloids Surf. A, 480, 122 (2015); https://doi.org/10.1016/j.colsurfa.2014.09.035.

23. E.D. Goddard and G.C. Benson, Can. J. Chem., 35, 986 (1957); https://doi.org/10.1139/v57-134

24. C.L. Mesa, J. Phys. Chem., 94, 323 (1990); https://doi.org/10.1021/j100364a054.

25. E.H. Crook, G.F. Trebbi and D.B. Fordyce, J. Phys. Chem., 68, 3592 (1964); https://doi.org/10.1021/j100794a026.

26. J.A. Stead and H. Taylor, J. Colloid Interface Sci., 30, 482 (1969); https://doi.org/10.1016/0021-9797(69)90417-2.

27. P. Mukerjee and A. Ray, J. Phys. Chem., 70, 2150 (1966); https://doi.org/10.1021/j100879a014.

28. J.E. Adderson and H. Taylor, J. Colloid Sci., 19, 495 (1964); https://doi.org/10.1016/0095-8522(64)90065-0.

29. G.M. Musbally, G. Perron and J.E. Desnoyers, J. Colloid Interface Sci., 54, 80 (1976); https://doi.org/10.1016/0021-9797(76)90287-3.

30. B.D. Flockhart, J. Colloid Sci., 16, 484 (1961); https://doi.org/10.1016/0095-8522(61)90026-5

31. Y. Moroi, N. Nishikido, H. Uehara and R. Matuura, J. Colloid Interface Sci., 50, 254 (1975); https://doi.org/10.1016/0021-9797(75)90228-3.

32. L.-J. Chen, S.-Y. Lin and C.-C. Huang, J. Phys. Chem. B, 102, 4350 (1998); https://doi.org/10.1021/jp9804345.

33. S.B. Sulthana, S.G.T. Bhat and A.K. Rakshit, Colloids Surf. A, 111, 57 (1996); https://doi.org/10.1016/0927-7757(95)03491-9.

34. S.K. Mehta, K.K. Bhasin, R. Chauhan and S. Dham, Colloids Surf. A, 255, 153 (2005); https://doi.org/10.1016/j.colsurfa.2004.12.038.

35. J.P. Marcolongo and M. Mirenda, J. Chem. Educ., 88, 629 (2011); https://doi.org/10.1021/ed900019u.

36. D.N. Rubingh, in ed.: K.L. Mittal, Mixed Micelle Solutions, In: Solution Chemistry of Surfactants, Plenum Press, New York, vol. 1, p. 337 (1979).

37. P.M. Holland and D.N. Rubingh, J. Phys. Chem., 87, 1984 (1983); https://doi.org/10.1021/j100234a030.

38. J.H. Clint, J. Chem. Soc., Faraday Trans. I, 71, 1327 (1975); https://doi.org/10.1039/f19757101327.

39. K.J. Mysels and R.J. Otter, J. Colloid Sci., 16, 462 (1961); https://doi.org/10.1016/0095-8522(61)90023-X.

40. D.F. Evans and P.J. Wightman, J. Colloid Interface Sci., 86, 515 (1982); https://doi.org/10.1016/0021-9797(82)90096-0.

41. J.R. Rodríguez, A. González-Pérez, J.L. Del Castillo and J. Czapkiewicz, J. Colloid Interface Sci., 250, 438 (2002); https://doi.org/10.1006/icis.2002.8362.

42. G. Sugihara and M. Hisatomi, J. Colloid Interface Sci., 219, 31 (1999); https://doi.org/10.1006/jcis.1999.6378.

43. R. Lumry and S. Rajender, Biopolymers, 9, 1125 (1970); https://doi.org/10.1002/bip.1970.360091002. 